\title{
Thermal Destruction of Waste Insulating Oil Containing PCBs under High Temperature and Pressurized Conditions
}

\author{
Min-Gwang Seok ${ }^{1}$, Gang-Woo Lee ${ }^{1}$, Jae-Jeong Lee ${ }^{1}$, Min-Choul Kim ${ }^{1}$, Yang-Do Kim² \\ Jong-Hyeon Jung ${ }^{3}$, Byung-Hyun Shon ${ }^{4 \dagger}$ \\ ${ }^{1}$ Yoo Sung Co. Ltd., Research \& Development Center, Ulsan 689-892, Korea \\ ${ }^{2}$ School of Materials Science and Engineering, Pusan National University, Busan 609-735, Korea \\ ${ }^{3}$ Faculty of Health Science, Daegu Haany University, Daegu 706-060, Korea \\ ${ }^{4}$ Department of Environmental Engineering, Hanseo University, Seosan 356-706, Korea
}

\begin{abstract}
This experimental study was performed to obtain thermal energy from the combustion of synthetic gas, produced by the pyrolysis of insulating oil containing polychlorinated biphenyls (PCBs) in a high temperature and high pressure reactor. The average synthetic gas generated was $59.67 \mathrm{Am}^{3} / \mathrm{hr}$ via the steady state gasification of insulating oil waste $(20 \mathrm{~kg} / \mathrm{hr}$ ) with average concentrations (standard deviation) of $\mathrm{CO}_{2}, \mathrm{CO}$, and $\mathrm{H}_{2}$ in the synthetic gas of $38.63 \pm 3.11 \%, 35.18 \pm 1.93 \%$, and $28.42 \pm 1.68 \%$, respectively. The concentrations of the PCBs in the transformer insulating oil and synthetic gas after its gasification, and the concentrations of the dioxins that could be produced from the incomplete degradation of PCBs were measured. It was revealed that the PCBs in the insulating oil were composed

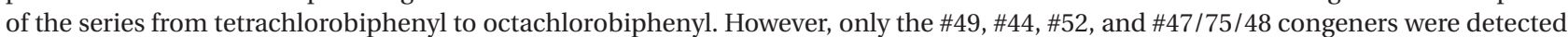
from the synthetic gas after gasification of the insulating oil and in the flue gas from the combustor. In conclusion, the experimental conditions suggested in this study were very useful for the appropriate treatment of insulating oil containing PCBs. Also, fuel gas containing $\mathrm{CO}$ and $\mathrm{H}_{2}$ can be obtained from the pyrolysis of insulating oil containing PCBs.
\end{abstract}

Keywords: Dioxins, Gasification, High temperature and pressure, Insulating oil, PCBs

\section{Introduction}

Polychlorinated biphenyls (PCBs) are a broad family of manmade organic chemicals known as chlorinated hydrocarbons. Overall, they are materials where a hydrogen atom bonded to the biphenyl radical $\left(\mathrm{C}_{12} \mathrm{H}_{10}\right)$ is substituted with a chlorine atom. There are 209 congeners, which depend on the quantity and location of the substituted chlorine atom. The PCBs are characterized by strong toxicity, residual persistence, long range mobility and the accumulation in living bodies, and have been used as insulating oil in transformers, capacitors, lubricants, plasticizers and paints as they possess excellent electric insulation and chemical stability properties. However, they are also classified as carcinogens and have been reported to damage nerves, procreation and the immune system [1]. The strong toxicity and residual persistence of PCBs have been known since PCB residues in fish and eagles were reported by Jensen et al. [2] in 1969. Every country in the world, initiated by the USA in 1979, has prohibited the manufacture and use of PCBs [1]. The manufacture import and use of PCBs in Korea have been banned since 1996, with products regulated for treatment as specified wastes when they contain more than $2 \mathrm{ppm}$ (over $2 \mathrm{mg} / \mathrm{L}$ in liquid state). The reason for using transformers containing PCBs in South Korea is that insulating oils produced prior to the ban still remain or are used in the new transformer or PCBs remain inside the transformer due to their absorption.

PCBs were first synthesized by Schmidt in 1881, and have been produced in Germany, UK, and Japan since their first commercial production by Monsanto Company (St. Louis, MO, USA) in 1929. The names of commercially produced PCBs differ according to their country of origin. They are called as Aroclor in USA, Phenoclor in France, Kaneclor in Japan, and Delor in Czech. The quantity of PCBs produced globally between 1930s and 1970s is uncertain, but has been estimated to be approximately $60,000-2,000,000$ tons [3], with around 130 congeners usually found in commercially utilized PCB mixtures [4].

Chemical methods, such as high temperature incineration, dechlorination and hydrotreatment, are used for the degradation of PCBs, and PCBs are known to be degraded up to $99.9999 \%$ via incineration at high temperature [5]. However, toxic substances, such as polychlorinated dibenzofurans (PCDFs) and polychlorinated dibenzodioxins (PCDDs), are produced from PCBs during

Received January 25, 2012 Accepted August 19, 2012

cc This is an Open Access article distributed under the terms of the Creative Commons Attribution Non-Commercial License (http://creativecommons. org/licenses/by-nc/3.0/) which permits unrestricted non-commercial use, distribution, and reproduction in any medium, provided the original work is properly cited.
${ }^{\dagger}$ Corresponding Author

E-mail: bhshon@hanseo.ac.kr

Tel: +82-41-660-1368 Fax: +82-41-660-1368 


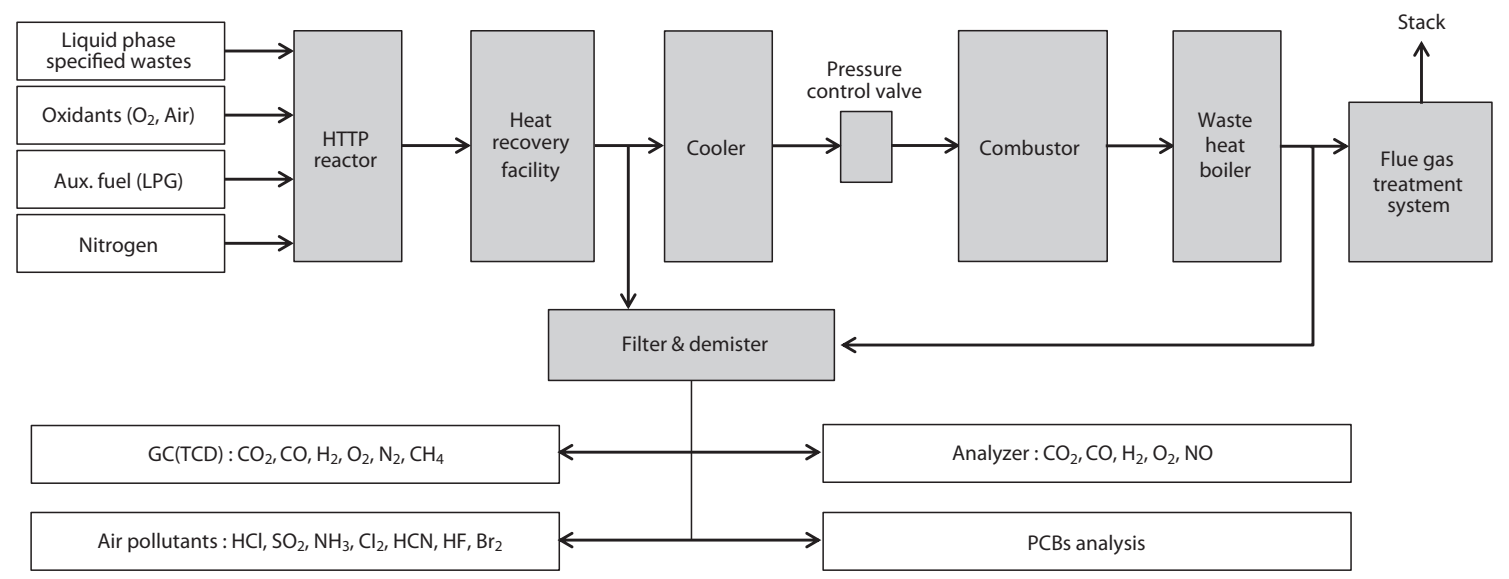

Fig. 1. Schematic diagrams of the high temperature and pressure gasification (HTPG) treatment system. GC: gas chromatography, TCD: thermal conductivity detector, PCB: polychlorinated biphenyl.

the combustion process if incineration is not appropriately controlled. It has been reported that PCDFs are produced from the incineration of specified wastes containing about $1 \%$ PCBs [6].

Various harmful compounds are emitted into the air when waste oil and agrochemical wastes containing high concentrations of inter-halogen compounds, such as PCBs and aromatic compounds are not satisfactorily treated by the traditional incineration method (at atmospheric pressure, $850-1,100^{\circ} \mathrm{C}$ ). Therefore, since the 1990s, Japan, USA, and European countries have shown interest in the development of a gasification system as a substitute for the traditional incineration system. A number of large scale plants for the gasification of coal or heavy oil residues have been established in the USA and Europe over the last 30 years [7], while in Japan a number of waste gasification processes are currently proposed ( 8 facilities are operated and about 100 facilities are ordered). Gasification systems have many advantages, such as the reuse of the synthetic gas generated by gasification, the prevention of dioxin formations, and the reduction of various air pollutants. Research on pressurized gasification and combustion has energetically advanced with the aim of utilizing coal more cleanly and efficiently. It has been reported that coals evolution, i.e., its devolatilization with heterogeneous reactions and the gas phase reaction, at rapid heating under high pressure differ greatly from the case of normal pressure [8]. Consequently, it is necessary to develop an innovative incineration system by introducing gasification technology for the harmless processing of non-degradable liquid wastes. The purpose of this study was to develop a commercial high temperature and pressure gasification (HTPG) system for treating PCBs in insulating oil. The insulating oil waste containing PCBs could be converted into synthetic gas, which is mainly composed of $\mathrm{H}_{2}$ and $\mathrm{CO}$ via gasification under the condition of a temperature higher than $1,400^{\circ} \mathrm{C}$ and a maximum pressure of $4 \mathrm{kgf} / \mathrm{cm}^{2}(\mathrm{~g})$. The destruction and removal efficiency (DRE) of PCBs, characteristics of gasification, and the emissions of air pollutants were studied to confirm the efficiency of the HTPG system. The effect of the equivalence ratio on the synthetic gas contents was also studied to quantify the gasification of the insulating oil containing PCBs.

\section{Materials and Methods}

\subsection{Experimental Equipment}

Experiments were carried out in a 3 ton/day scale HTPG pilot plant system, as shown in Fig. 1. This experimental apparatus was comprised of a feeding system for the liquid waste and associated utilities (LPG, $\mathrm{O}_{2}, \mathrm{~N}_{2}$, air, water and electric power, etc.), an HTPG reactor, heat recovery facilities, cooling system, pressure control valve, combustor, waste heat boiler, flue gas treatment system, and an analysis system.

The temperature of the HTPG reactor was set at $1,400^{\circ} \mathrm{C}$. In order to maintain this temperature prior to the main experiment, the HTPG reactor was preheated with LPG for $24 \mathrm{hr}$. Insulating oil waste containing PCBs was then injected into the reactor via an injection burner, with the oxidants $\left(\mathrm{O}_{2}\right.$, air) fed using mass flow controllers. The total feeding rate of the insulating oil waste through the reactor was maintained at $20 \mathrm{~kg} / \mathrm{hr}$ (residence time, $2-3 \mathrm{sec}$ ), with the reaction temperature and pressure varied within the ranges $1,400-1,600^{\circ} \mathrm{C}$ and $0-4 \mathrm{kgf} / \mathrm{cm}^{2}(\mathrm{~g})$, respectively. The operating conditions, especially the temperature and

Table 1. The physical properties of the LPSW and the experimental variables

\begin{tabular}{lc}
\hline Physical properties of IOW & \\
High heating value $(\mathrm{kcal} / \mathrm{kg})$ & 10,975 \\
Operating pressure $\left(\mathrm{kgf} / \mathrm{cm}^{2}\right)$ & $<4$ \\
Proximate analysis $($ as received) $(\%)$ & \\
Moisture & 2.20 \\
Ash & 0.30 \\
$\quad$ Volatile & 97.50 \\
Experimental variables & \\
Operating temperature $\left({ }^{\circ} \mathrm{C}\right)$ & $1,400-1,600$ \\
IOW feeding rate $(\mathrm{kg} / \mathrm{hr})$ & 20 \\
Residence time $(\mathrm{sec})$ & $2-3$ \\
Oxidants $(\mathrm{L} / \mathrm{min})$ & \\
$\mathrm{O}_{2}$ & $<410$ \\
Air & $<200$ \\
\hline
\end{tabular}

LPSW: liquid phase specified wastes, IOW: insulating oil waste. 

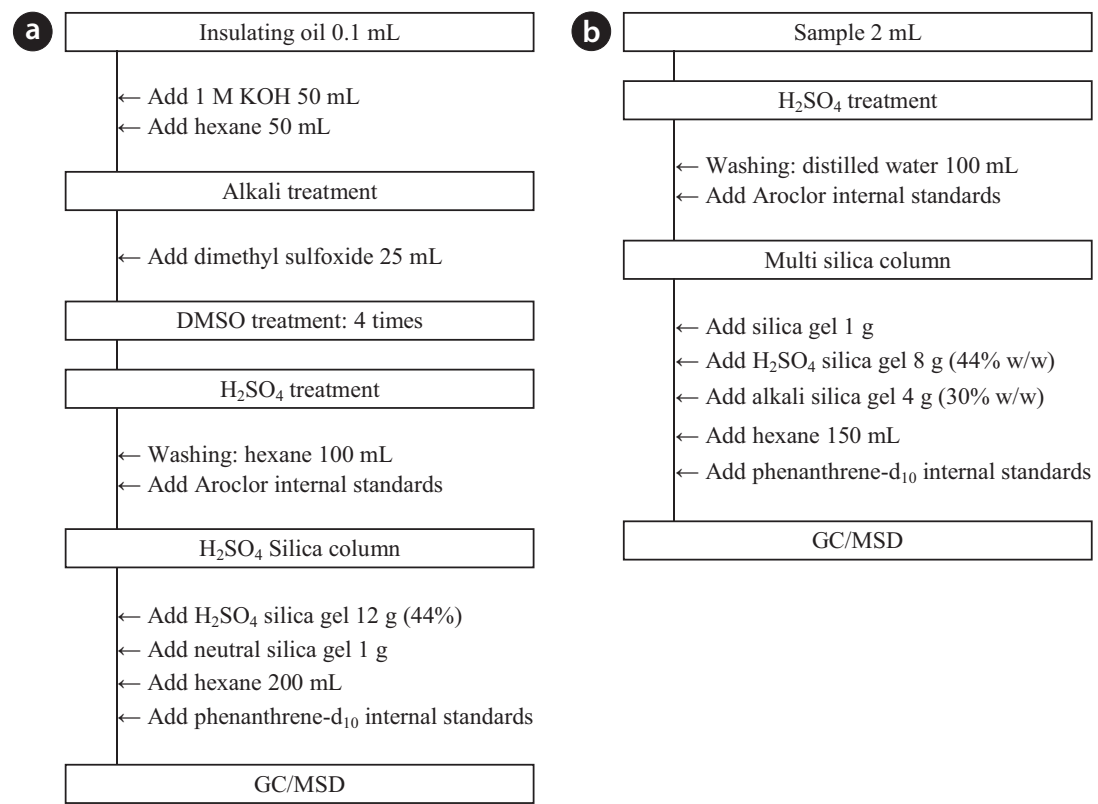

Fig. 2. Analytical procedures for the polychlorinated biphenyls (PCBs) in the insulating oil waste (a) and syngas (b). DMSO: dimethyl sulfoxide, GC/MSD: gas chromatography-mass selective detector.

pressure, in the reactor were controlled by varying the feeding rate of the insulating oil waste, oxidant flow rate, oxidant/fuel ratio, and pressure.

After the decomposition of the insulating oil waste in the HTPG reactor, the flue gas (synthetic gas) was rapidly cooled from $1,400^{\circ} \mathrm{C}$ to $200^{\circ} \mathrm{C}$ at the heat recovery facility. This rapid temperature reduction avoided the reformation of dioxins, furans and other organic compounds from elementary molecules in the synthetic gas due to the de novo synthetic back reactions [6]. At the cooling tower, the synthetic gas was cooled to $20^{\circ} \mathrm{C}$ by spraying water through the gas to protect the equipment being used. The synthetic gas generated from the HTPG reactor was burned in the combustor, and recycled as steam by the waste heat boiler. The pollutants in flue gas were then removed via the flue gas treatment equipment. The physical properties of the insulating oil waste and the experimental variables are listed in Table 1. The insulating oil waste containing PCBs used for gasification contain $2.2 \%$ moisture, $97.50 \%$ volatile matter, and $0.30 \%$ ash, with a higher heating value (HHV) of 10,975 kcal $/ \mathrm{kg}$.

\subsection{Sampling and Analysis}

BP-MS (Wellington Laboratories Inc., Guelph, ON, Canada) was used as an internal standard, comprising of a mixture of $62{ }^{13} \mathrm{C}_{12}$-PCB congeners. The detailed lists are shown in Table 2 .

To analyze the 209 PCBs, the peaks for the retention times of each congener were checked against the standard materials of the 62 PCBs from the Wellington laboratories and that for Aroclor, a commercial PCB used in transformers. Five different concentrations of the Aroclor standard solution for the calibration curve were prepared $(10,50,100,200$, and $500 \mathrm{ng} / \mathrm{mL})$, and showed excellent linearity with an $\mathrm{R}^{2}$ value greater than 0.99 . The PCBs were then identified and quantified using gas chromatography-mass seletive detector (GC/MSD), with a DB-5MS (5\%-phenyl-methylpolysiloxane) column. The oven temperature was held at $70^{\circ} \mathrm{C}$ for $2 \mathrm{~min}$, then raised to $170^{\circ} \mathrm{C}$ at a rate of $30^{\circ} \mathrm{C} / \mathrm{min}$, followed by a rate of $5^{\circ} \mathrm{C} / \mathrm{min}$ to $300^{\circ} \mathrm{C}$, and held at this temperature for $4 \mathrm{~min}$. The analytical conditions of the GC/MSD (Agilent 6890 GC/5973 MSD; Santa Clara, CA, USA) for the analysis of the PCBs in insulating oil waste are listed in Table 3 , with the detailed analytical procedures shown in Fig. 2. PCB congeners were identified using the International Union of Pure and Applied Chemistry (IUPAC) numbering systems [9, 10]. The toxicity equivalency quantity (TEQ) values for dl-PCB (dioxin like-PCB) were calculated by multiplying the toxic equivalency factors [11]. Table 4 shows the analytical conditions for the GC/ MSD analysis of the dioxins in the synthetic gas.

The concentrations of 15 air pollutants emitted from the combustor were continuously monitored and analyzed in duplicate, including $\mathrm{NH}_{3}, \mathrm{HCl}, \mathrm{Cl}_{2}, \mathrm{CS}_{2}, \mathrm{SOx}, \mathrm{HCHO}, \mathrm{C}_{6} \mathrm{H}_{6}, \mathrm{C}_{6} \mathrm{H}_{5} \mathrm{OH}, \mathrm{H}_{2} \mathrm{~S}$, $\mathrm{HCN}$, vinyl chloride, fluorine, bromine, mercury, and arsenic.

Table 2. Sixty-two polychlorinated biphenyl (PCB) congeners in the BP-MS (Wellington Laboratories)

\begin{tabular}{ll}
\hline \multicolumn{1}{c}{ PCB congener } & \multicolumn{1}{c}{ IUPAC no. } \\
\hline Monochlorobiphenyl & 1,3 \\
Dichlorobiphenyl & $4,8,10,15$ \\
Trichlorobiphenyl & $18,19,22,28,33,37$ \\
Tetrachlorobiphenyl & $44,49,52,54,70,74,77,81$ \\
Pentachlorobiphenyl & $87,95,99,101,104,105,110,114,118,119,123,126$ \\
Hexachlorobiphenyl & $128,138,149,151,153,155,156,157,158,167,168,169$ \\
Heptachlorobiphenyl & $170,171,177,178,180,183,187,188,189,191$ \\
Octachlorobiphenyl & $194,199,201,202,205$ \\
Nonachlorobiphenyl & 206,208 \\
Decachlorobiphenyl & 209 \\
\hline
\end{tabular}

IUPAC: International Union of Pure and Applied Chemistry. 
Table 3. Analytical conditions for the GC/MSD analysis of the PCBs in insulating oil waste

\begin{tabular}{cll}
\hline & & \multicolumn{1}{c}{ Conditions } \\
\hline GC & Column & DB-5MS $(5 \%$-phenyl-methylpolysiloxane $)$ \\
& & $(60 \mathrm{~m}$ length $\times 0.32 \mathrm{~mm} \mathrm{ID} \times 0.25 \mu \mathrm{m}$ film thickness $)$ \\
& Carrier gas & $\mathrm{He}(99.999 \%)$ at $1.0 \mathrm{~mL} / \mathrm{min}$ \\
& Injection port temperature $\left({ }^{\circ} \mathrm{C}\right)$ & 250 \\
& Injection mode & Splitless, $2 \mathrm{uL}$ injection \\
& Oven temperature programming & $70^{\circ} \mathrm{C}(2 \mathrm{~min}) \rightarrow 30^{\circ} \mathrm{C} / \mathrm{min} \rightarrow 170^{\circ} \mathrm{C} \rightarrow 5^{\circ} \mathrm{C} / \mathrm{min} \rightarrow 300^{\circ} \mathrm{C}(4 \mathrm{~min})$ \\
MS & Interface temperature $\left({ }^{\circ} \mathrm{C}\right)$ & 280 \\
& Ionization mode & Electron ionization \\
& Electron energy $(\mathrm{eV})$ & 70 \\
& Ion source temperature $\left({ }^{\circ} \mathrm{C}\right)$ & 230 \\
& Detection mode & Selected ion monitoring
\end{tabular}

GC/MSD: gas chromatography-mass selective detector, MC: mass spectrometry, PCB: polychlorinated biphenyl, ID: inner diameter.

Table 4. Analytical condition for the GC/MSD analysis of the dioxins in the syngas

\begin{tabular}{|c|c|c|}
\hline Items & 4-6 Chlorine dioxins & 7-8 Chlorine dioxins \\
\hline GC/MS & HP6890GC/JMS700DMS & HP6890GC/JMS700DMS \\
\hline Column & Supelco SP-2331 $(60 \mathrm{~m} \times 0.25 \mathrm{~mm} \times 0.20 \mu \mathrm{m})$ & DB-5MS $(30 \mathrm{~m} \times 0.25 \mathrm{~mm} \times 0.25 \mu \mathrm{m})$ \\
\hline Oven & $\begin{aligned} 100^{\circ} \mathrm{C}(1 \mathrm{~min}) & \rightarrow 20^{\circ} \mathrm{C} / \mathrm{min} \rightarrow 200^{\circ} \mathrm{C} \rightarrow 2^{\circ} \mathrm{C} / \mathrm{min} \\
& \rightarrow 250^{\circ} \mathrm{C}(29 \mathrm{~min})\end{aligned}$ & $\begin{aligned} 150^{\circ} \mathrm{C}(1 \mathrm{~min}) & \rightarrow 10^{\circ} \mathrm{C} / \mathrm{min} \rightarrow 250^{\circ} \mathrm{C} \rightarrow 5^{\circ} \mathrm{C} / \mathrm{min} \\
& \rightarrow 3,000^{\circ} \mathrm{C}(4 \mathrm{~min})\end{aligned}$ \\
\hline Carrier gas $(\mathrm{mL} / \mathrm{min})$ & Helium 1.2 & Helium 1.2 \\
\hline Injection mode & Splitless & Splitless \\
\hline Ionization mode & El+ & $\mathrm{El}+$ \\
\hline Ionization energy $(\mathrm{eV})$ & 38 & 38 \\
\hline Injector $\left({ }^{\circ} \mathrm{C}\right)$ & 250 & 280 \\
\hline Ion source $\left({ }^{\circ} \mathrm{C}\right)$ & 250 & 280 \\
\hline Resolution & Above 10,000 & Above 10,000 \\
\hline
\end{tabular}

GC/MS: gas chromatography-mass spectrometry, GC/MSD: gas chromatography-mass selective detector, PCB: polychlorinated biphenyl.

\section{Results and Discussion}

\subsection{Characteristics of Gasification}

The temperature change in the reactor was monitored in order to check the operational stability of the reactor as the experiments were performed at very high temperature and high pressure. The temperature of the reactor was controlled by the flow rates of air and pure oxygen. The temperature changes were analyzed at 3 points inside the reactor, as shown in Fig. 3 . As seen from Fig. 3, the temperature sharply increased after the injection of the insulating oil, but then showed a decreasing trend during the transition stage from oxidation to gasification. The temperatures at the outlet, center and top of the gasifier were maintained at $1,570^{\circ} \mathrm{C}, 1,540^{\circ} \mathrm{C}$, and $1,420^{\circ} \mathrm{C}$, respectively, during the gasification stage from 200 to $400 \mathrm{~min}$ after the gasification reaction. The temperatures of the heat exchanger and cooler were $145^{\circ} \mathrm{C}$ and $20^{\circ} \mathrm{C}$, respectively.

The major components from the gasification reaction were $\mathrm{CO}$ and $\mathrm{H}_{2}$, which have high heating values (chemical energy). This chemical energy can be recycled using a gas or steam turbine [12]. The composition and quantity of the synthetic gas obtained through gasification was dependent on the characteristics of the wastes, air (or oxygen) and steam flow rates, and reaction temperature. Synthetic gas has been found to have a heating value of $1,800-2,500 \mathrm{kcal} / \mathrm{Sm}^{3}$ when oxygen was used, but only $1,000 \mathrm{kcal} / \mathrm{Sm}^{3}$ when air was used [13].

Fig. 4 reveals the characteristics of the synthetic gas $\left(\mathrm{H}_{2}, \mathrm{CO}\right.$, and $\mathrm{CO}_{2}$ ) generated from the gasification reaction. As seen in Fig. 4 , during the early stages, the experiment was performed under oxidation conditions, but then converted to the gasification reaction when the experimental conditions had stabilized, i.e., the temperature and pressure inside the reactor. The concentration of oxygen in the synthetic gas decreased below $5 \%$ after 90 min of the gasification reaction. The oxygen concentrations during the steady state gasification reaction, from 200 to $400 \mathrm{~min}$, ranged from $0.24 \%$ to $0.36 \%$, with an average concentration (standard deviation) of $0.27 \pm 0.0119 \%$. The highest concentration of $\mathrm{CO}_{2}$ at the moment of conversion from oxidation to gasification was greater than $60 \%$, which steadily decreased to within the range of $44.10 \%$ to $32.80 \%$, with an average concentration (standard deviation) of $38.63 \pm 3.11 \%$ during the steady state gasification step. The concentration of $\mathrm{H}_{2}$ rapidly increased during the initial stage of the gasification reaction, and ranged between $31.30 \%$ 


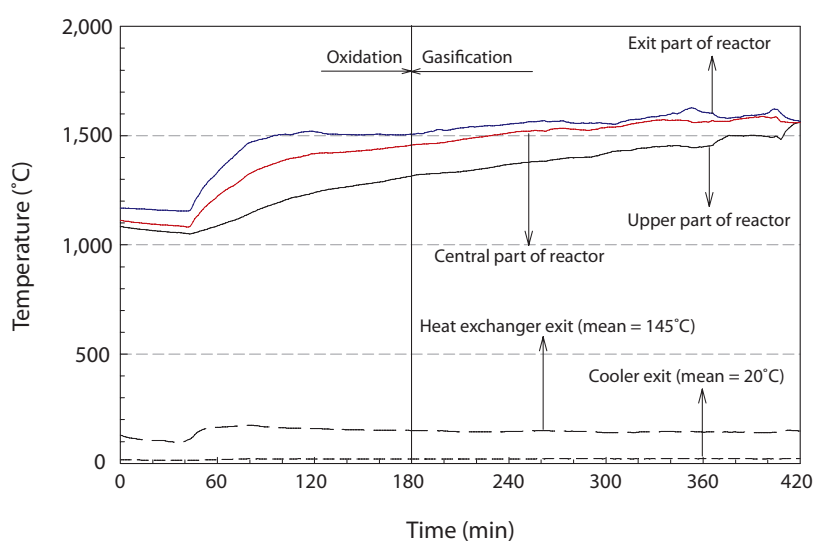

Fig. 3. Temperature profiles in the high temperature and pressure gasification reactor, heat exchanger, and cooler.

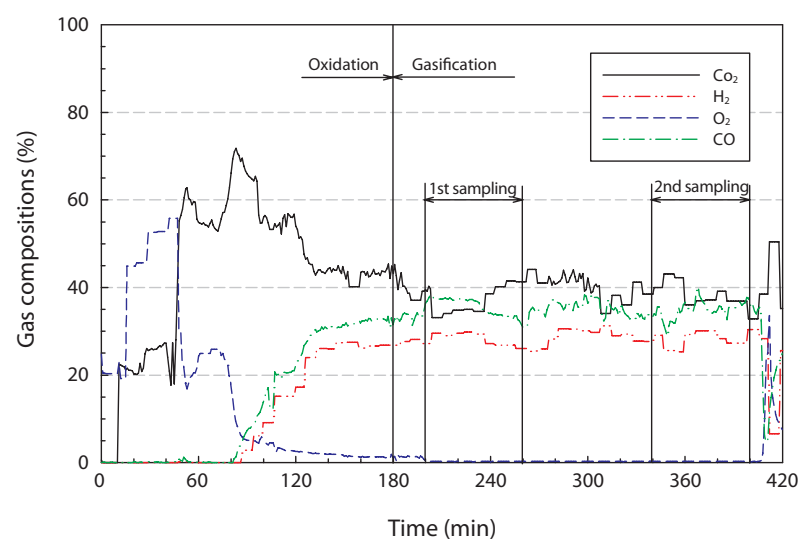

Fig. 4. Composition of the synthetic gas versus reaction time and reaction state.

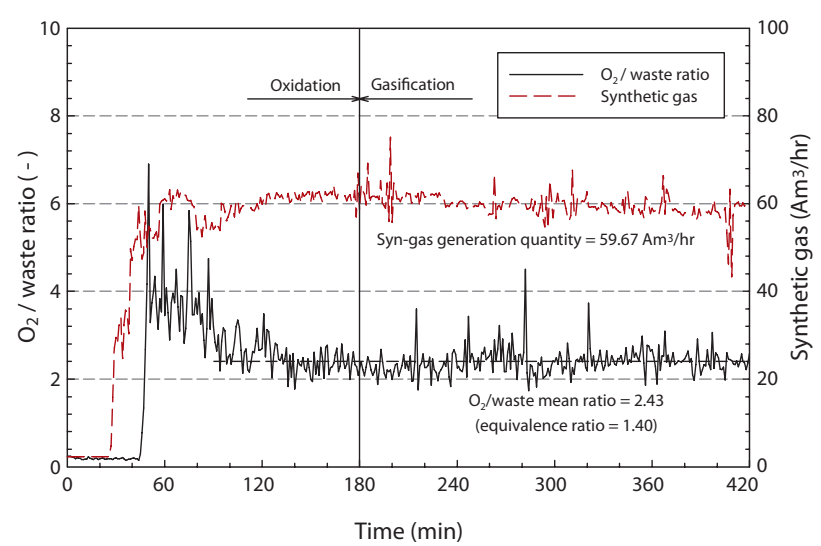

Fig. 5. The ratio of $\mathrm{O}_{2} /$ waste and the generation of synthetic gas versus reaction time and reaction state.

and $25.30 \%$ during the steady state gasification stage, with an average concentration (standard deviation) of $28.42 \pm 1.68 \%$. For CO, the concentration ranged between $40.13 \%$ and $28.98 \%$, with an average concentration (standard deviation) of $35.18 \pm 1.93 \%$, during the steady state gasification stage.

One of the indices for evaluating the thermal efficiency of a

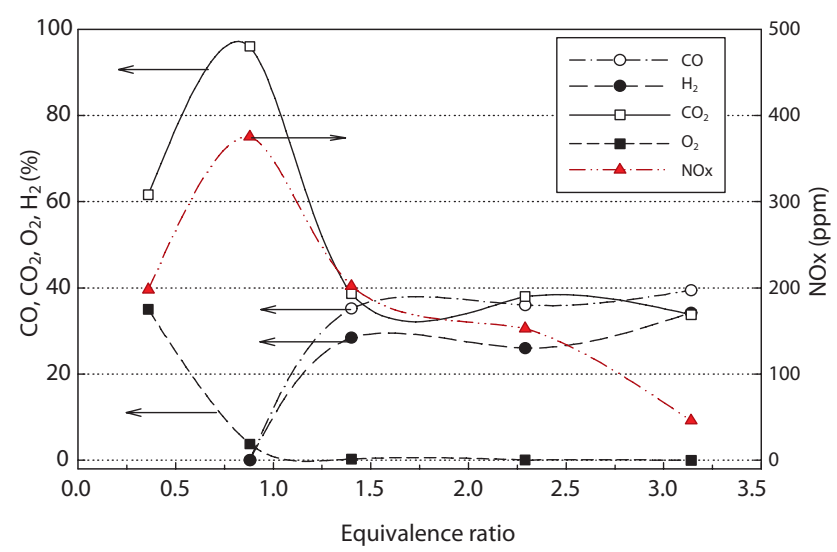

Fig. 6. Composition of synthetic gas versus the equivalence ratio (reaction temperature, $1,500^{\circ} \mathrm{C}$ ).

gasification reaction is cold gas efficiency (CGE), which shows the degree of energy collected in terms of chemical energy from the raw feedstock. The CGE of coal and wastes are well known to be roughly $65-80 \%$ and a maximum of $60 \%$, respectively [14]. The CGE can be calculated using Eq. (1). The average heating value and CGE of the synthetic gas generated through the gasification reaction of the insulating oil were $1,929 \mathrm{kcal} / \mathrm{Sm}^{3}$ and $49.21 \%$, respectively. The lower heating values of $\mathrm{CO}$ and $\mathrm{H}_{2}$ used for the calculation were 3,019 and $2,580 \mathrm{kcal} / \mathrm{Sm}^{3}$, respectively.

Cold gas efficiency (CGE)

$=$ (Heating value of product gas/Heating value in feedstock $)$ $\times 100$

$=\left[\left(\right.\right.$ Heating value of $\mathrm{CO}+$ Heating value of $\left.\mathrm{H}_{2}\right) /($ Heating value of feedstock) $] \times 100$

From Eq. (1)

Cold gas efficiency of insulating oil

$=[(16.50 \mathrm{kcal} / \mathrm{sec}+11.39 \mathrm{kcal} / \mathrm{sec}) /(56.66 \mathrm{kcal} / \mathrm{sec})] \times 100$

$=[(27.88 \mathrm{kcal} / \mathrm{sec}) /(56.66 \mathrm{kcal} / \mathrm{sec})] \times 100=49.21 \%$

Fig. 5 illustrates the ratio of insulating oil to oxidant $\left(\mathrm{O}_{2}\right)$ and the generation of synthetic gas according to the reaction time. As shown in Fig. 5, the equivalence ratio $(\varphi)$, as defined in Eq. (1) was 1.40 , with an average synthetic gas generation rate of 59.67 $\mathrm{am}^{3} / \mathrm{hr}$.

$$
\varphi=(\mathrm{F} / \mathrm{O}) /(\mathrm{F} / \mathrm{O}) \text { stoich }
$$

Where, the $(\mathrm{F} / \mathrm{O})$ is the fuel-oxygen ratio, and $(\mathrm{F} / \mathrm{O})$ stoich is the theoretical fuel-oxygen ratio.

In this study, the equivalence ratio and synthetic gas generation rate remained constant, with only slight fluctuation. From these results, the equivalence ratio and synthetic gas generation rate can potentially be calculated.

Fig. 6 shows the concentration of synthetic gas with change in the equivalence ratio. As seen in Fig. 6, mostly $\mathrm{CO}_{2}$ was generated at an equivalence ratio of less than 1 (fuel lean or oxidizer rich). However when the equivalence ratio was over 1.4, a steady state gasification reaction was obtained, at which point, the maximum concentrations of $\mathrm{CO}$ and $\mathrm{H}_{2}$ were achieved. In addition, stable gasification was obtained at an equivalence ratio of approximately 1.4 , as the rates of $\mathrm{CO}$ and $\mathrm{H}_{2}$ generation did not increase much, even when the equivalence ratio was increased. 


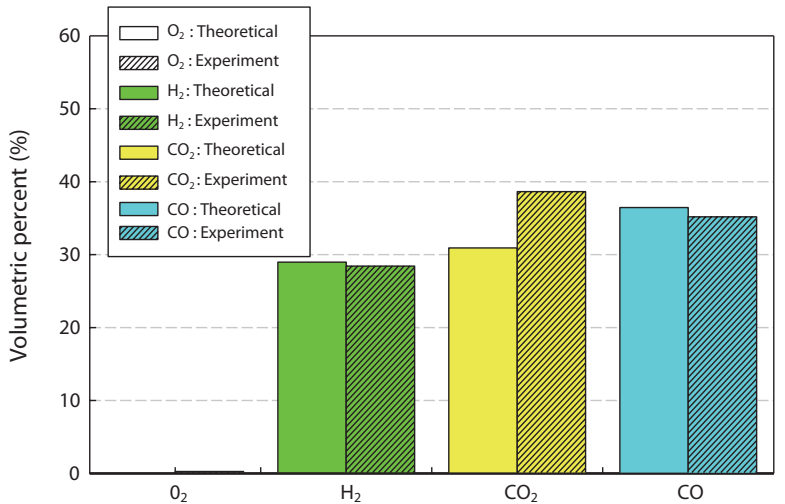

Fig. 7. Comparison of the experimental and simulated synthetic gas compositions (equivalence ratio, 1.40; reaction temperature, $\left.1,500^{\circ} \mathrm{C}\right)$.

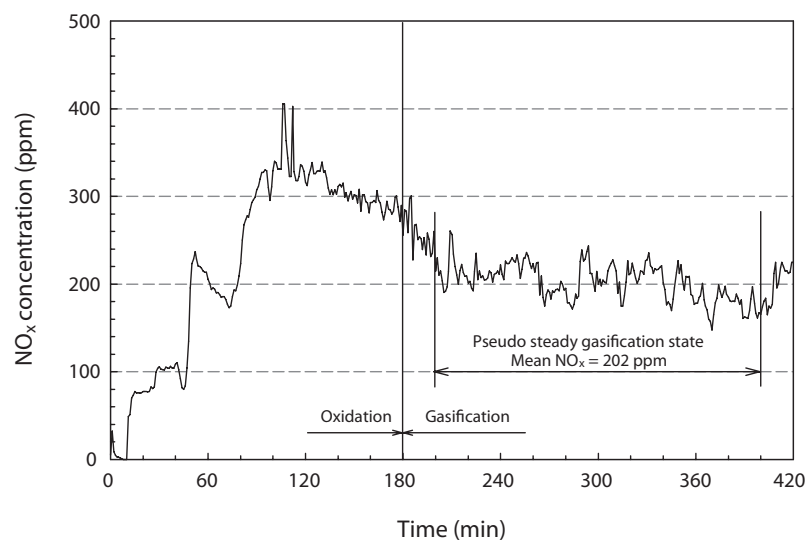

Fig. 8. Changes in the NOx concentration versus reaction time (equivalence ratio, 1.40 ; reaction temperature, $1,500^{\circ} \mathrm{C}$ ).

The concentrations of $\mathrm{CO}$ and $\mathrm{H}_{2}$ rapidly increased under the theoretical equivalence ratio $(\varphi=1.0)$ and fuel rich conditions, which was considered to be due to the low oxygen concentration in the synthetic gas [15].

Fig. 7 shows the comparison of the synthetic gas compositions generated experimentally and via the simulation result from the gasification of insulation oil. The material and thermal balance in the reactor were calculated using Hysys (Aspen Technology Inc., Burlington, MA, USA), which is a process simulation program, with the chemical equilibrium model used by minimizing the Gibbs free energy [14]. As shown in Fig. 7, the theoretical and experimental values did not reveal large differences for $\mathrm{CO}$ and $\mathrm{H}_{2}$, but about an $8 \%$ error was observed in the case of $\mathrm{CO}_{2}$. This was thought to be due to the real time changes in the material compositions (insulating oil waste and etc.) during the experiment. The concentration of NOx showed a maximum at an equivalence ratio of around 1.0, but the concentration decreased with increasing equivalence ratio.

The concentration of NOx was continuously analyzed during the reaction under the equivalence ratio and temperature conditions of $1.4^{\circ} \mathrm{C}$ and $1,500^{\circ} \mathrm{C}$, respectively, to check for changes in the NOx concentration during the gasification process. As shown in Fig. 8, the NOx concentration reached a maximum just before the gasification reaction, and demonstrated a stable trend after a steady reduction. This was thought to be due to the increased temperature inside the reactor because the latent heat of synthetic gas was at a minimum, and accounts for the largest part of heat balance; the excess oxygen would be at its lowest just before the shift in the reaction from oxidation to reduction. In addition, this coincided with the general trend in regards to the inhibition of NOx formation, as it was under oxidizer lean conditions after the start of the gasification reaction. The steady state concentration of NOx was about 202 ppm under the experimental conditions used in this study.

\subsection{Decomposition of PCBs}

The decomposition ratio of the PCBs contained in the insulating oil was measured from the contents of PCBs existing in the transformer insulating oil and in the synthetic gas emitted after gasification of the insulating oil. The concentrations of the dioxin-like materials potentially formed due to the incomplete decomposition of PCBs were also measured. Fig. 9 shows the distribution of PCB congeners at 3 points, which include in the insulating oil waste, in the synthetic gas from the gasifier and in the flue gas from the combustor. Various PCB congeners were detected in the insulating oil. Tetrachlorobiphenyl and octachlorobiphenyl congeners were those mainly detected, but 12 dl-PCBs (\#77, \#81, \#126, \#169, \#105, \#114, \#118, \#123, \#156, \#157, $\# 167$, and \#189), which have similar toxicities to that of dioxin, were not detected.

In the contents analyses of PCBs regarding the synthetic gas emitted from the HTPG reactor after the decomposition of the insulating oil, the concentrations of congeners \#49, \#44, \#52, and \#47/75/48 from 2 analyses of each were 16.622 and $3.185 \mathrm{ng} / \mathrm{Sm}^{3}$, 34.595 and $9.138 \mathrm{ng} / \mathrm{Sm}^{3}, 345.338$ and $7.721 \mathrm{ng} / \mathrm{Sm}^{3}$, and 14.122 and $3.588 \mathrm{ng} / \mathrm{Sm}^{3}$, respectively. The $12 \mathrm{dl}$-PCBs, which have similar toxicities to that of dioxin, were not detected, as was the case with the insulating oil. In the PCBs contents analysis in regard to the flue gas emitted from the combustor, the concentrations for congeners \#49, \#44, \#52, and \#47/75/48 from 2 analyses of each were 0.025 and $0.012 \mathrm{ng} / \mathrm{Sm}^{3}, 0.059$ and $0.045 \mathrm{ng} / \mathrm{Sm}^{3}, 0.059$ and $0.046 \mathrm{ng} / \mathrm{Sm}^{3}$, and 0.027 and $0.013 \mathrm{ng} / \mathrm{Sm}^{3}$, respectively. The 12

Table 5. Destruction and removal efficiency of the PCBs in the insulating oil waste

\begin{tabular}{|c|c|c|c|c|c|c|}
\hline \multirow[t]{2}{*}{ Sampling } & \multirow{2}{*}{$\begin{array}{l}\text { Total feeding } \\
\text { mass of WIO } \\
(\mathrm{kg})\end{array}$} & \multirow{2}{*}{$\begin{array}{c}\text { Total syngas from } \\
\text { HTPG reactor } \\
\left(\mathrm{Sm}^{3}\right)\end{array}$} & \multirow{2}{*}{$\begin{array}{l}\text { Total flue gas from } \\
\text { combustor } \\
\left(\mathrm{Sm}^{3}\right)\end{array}$} & \multirow{2}{*}{$\begin{array}{c}\text { PCBs in WIO } \\
(\mathrm{mg} / \mathrm{L})\end{array}$} & \multicolumn{2}{|c|}{ PCBs (ng/Sm $\left.{ }^{3}\right)$} \\
\hline & & & & & HTPG reactor & Combustor \\
\hline $1 \mathrm{st}$ & 64.8219 & 182.5136 & 1221.3330 & 1.6472 & 55.9309 & 0.0945 \\
\hline 2nd & 36.8953 & 106.7264 & 760.5651 & 1.6472 & 19.6924 & 0.0969 \\
\hline
\end{tabular}

PCB: polychlorinated biphenyl, WIO: waste insulating oil, HTPG: high temperature and pressure gasification. 

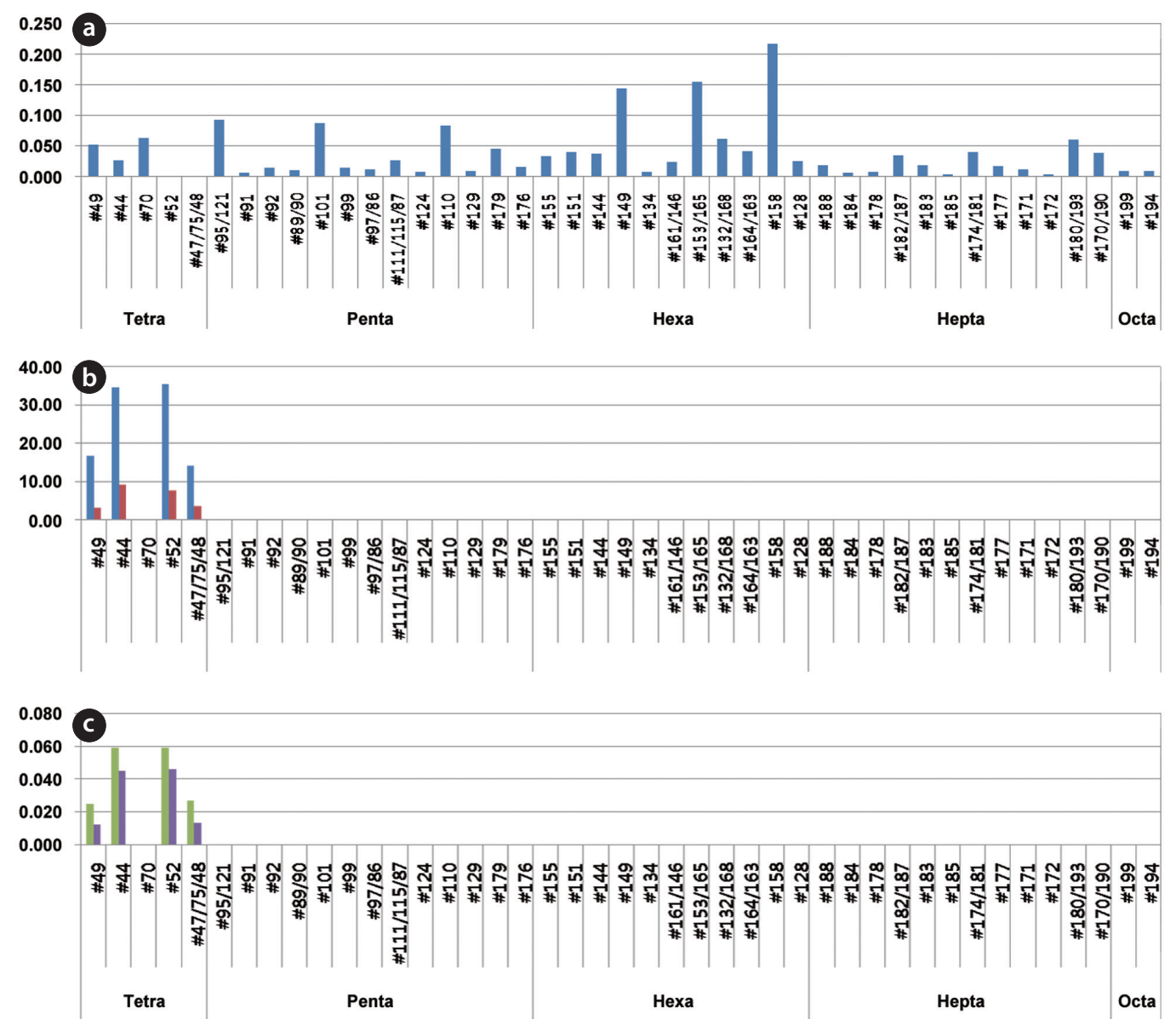

Fig. 9. Distribution of the polychlorinated biphenyl (PCB) congeners. Horizontal axis shows the International Union of Pure and Applied Chemistry no. of the PCB congeners, (a) in the insulating oil waste $(\mathrm{mg} / \mathrm{L}$ ), (b) in the synthetic gas generated from the high temperature and pressure gasification reactor $\left(\mathrm{ng} / \mathrm{Sm}^{3}\right)$, and (c) in the flue gas from the combustor $\left(\mathrm{ng} / \mathrm{Sm}^{3}\right)$.

dl-PCBs, which have similar toxicities to that of dioxin, were not detected, as was the case with the synthetic gas.

The DRE was calculated on the basis of the mass of the PCBs fed to the HTPG reactor minus those remaining in the exit of the HTPG reactor and in the combustor emissions, according to the following equation:

$$
\operatorname{DRE}(\%)=\left(1-\mathrm{W}_{\mathrm{o}} / \mathrm{W}_{\mathrm{i}}\right) \times 100(\%)
$$

Where $\mathrm{W}_{\mathrm{i}}$ is the mass of the sum for the PCBs entering the HTPG reactor and $\mathrm{W}_{\mathrm{o}}$ are those exiting the HTPG reactor and the combustor.

Table 5 shows the analyses of the PCB contents in the transformer insulating oil, the synthetic gas emitted from the HTPG reactor and the emission gas from the combustor; all analyses were conducted in duplicate. The DREs of the PCBs at each point were calculated using Eq. (3). The DREs of the PCBs after being in the HTPG reactor following gasification were $99.9911 \%$ and $99.9968 \%$, respectively, with an average of $99.9940 \%$. This HTPG reactor was found to be very effective for the gasification of insulating oil and in the treatment of the PCBs contained because the PCBs removed after passing through the combustor were $99.9999 \%$.

$$
\begin{aligned}
& \mathrm{DRE}_{\mathrm{HTPG} \text { reactor, 1st }}(\%)=\left(1-\mathrm{W}_{\mathrm{o}} / \mathrm{W}_{\mathrm{i}}\right) \times 100 \\
& \quad=\left(1-9.5114 \times 10^{-6} / 0.1068\right)=99.9911 \% \\
& \mathrm{DRE}_{\mathrm{HTPG} \text { reactor, 2nd }}(\%)=\left(1-\mathrm{W}_{\mathrm{o}} / \mathrm{W}_{\mathrm{i}}\right) \times 100 \\
& \quad=\left(1-1.9582 \times 10^{-6} / 0.0608\right)=99.9968 \% \\
& \mathrm{DRE}_{\text {total, } 1 \text { st }}(\%)=\left(1-\mathrm{W}_{\mathrm{o}} / \mathrm{W}_{\mathrm{i}}\right) \times 100 \\
& \quad=\left(1-1.0755 \times 10^{-7} / 0.1068\right)=99.9999 \% \\
& \mathrm{DRE}_{\text {total, } 2 \text { nd }}(\%)=\left(1-\mathrm{W}_{\mathrm{o}} / \mathrm{W}_{\mathrm{i}}\right) \times 100 \\
& \quad=\left(1-6.8685 \times 10^{-8} / 0.0608\right)=99.9999 \%
\end{aligned}
$$

Table 6 shows the concentrations of PCDDS and PCDFs measured during the gasification experiments carried out at $1,400^{\circ} \mathrm{C}$. The PCDDs are found to be at high concentrations compared to the PCDFs, which is the trend unusually observed [16]. In these analyses furans such as $1,2,3,4,6,7,8$-HpCDF, 1, 2, 3, 4, 7, 8, 9-HpCDF, and octachlorodibenzofuran (OCDF) were detected: as well as dioxins such as 1, 2, 3, 4, 6, 7, 8-HpCDD, and octachlorodibenzopdioxin (OCDD). Therefore, more chlorinated isomers for both PCDDs and PCDFs were formed in larger amounts than those less chlorinated, which was also observed in the results of Aracil et al. [14]. The dioxin-like material concentrations in the synthetic gas generated from the HTPG reactor from duplicate analyses were 12.107 and $15.135 \mathrm{pg}-\mathrm{TEQ} / \mathrm{Sm}^{3}$. This means that the HTPG reactor treated the PCBs in the insulating oil ad- 
Table 6. Dioxin concentrations in the synthetic gas generated from the HTPG plant

\begin{tabular}{|c|c|c|c|c|c|c|}
\hline \multirow{2}{*}{ Isomers } & \multirow{2}{*}{ WHO-TEF } & \multicolumn{2}{|c|}{$\mathrm{pg} / \mathrm{Sm}^{3}$ Sample } & \multicolumn{2}{|c|}{$\mathrm{pg}-\mathrm{TEQ} / \mathrm{Sm}^{3}$} & \multirow{2}{*}{ Remark } \\
\hline & & 1st & 2nd & 1st & 2nd & \\
\hline $2,3,7,8-\mathrm{TCDF}$ & 0.1 & 0.000 & 0.000 & 0.000 & 0.000 & \multirow{10}{*}{$\begin{array}{c}\text { Korean emission } \\
\text { standards } \\
100 \mathrm{pg}-\mathrm{TEQ} / \mathrm{Sm}^{3}\end{array}$} \\
\hline $1,2,3,7,8$-PeCDF & 0.005 & 0.000 & 0.000 & 0.000 & 0.000 & \\
\hline $2,3,4,7,8-\mathrm{PeCDF}$ & 0.5 & 0.000 & 0.000 & 0.000 & 0.000 & \\
\hline $1,2,3,4,7,8-\mathrm{HxCDF}$ & 0.1 & 0.000 & 0.000 & 0.000 & 0.000 & \\
\hline $1,2,3,6,8,9-\mathrm{HxCDF}$ & 0.1 & 0.000 & 0.000 & 0.000 & 0.000 & \\
\hline $1,2,3,7,8,9-\mathrm{HxCDF}$ & 0.1 & 0.000 & 0.000 & 0.000 & 0.000 & \\
\hline $2,3,4,6,8,9-\mathrm{HxCDF}$ & 0.1 & 0.000 & 0.000 & 0.000 & 0.000 & \\
\hline $1,2,3,4,6,7,8-\mathrm{HpCDF}$ & 0.01 & 0.000 & 486.461 & 0.000 & 4.865 & \\
\hline $1,2,3,4,7,8,9-\mathrm{HpCDF}$ & 0.01 & 350.139 & 192.646 & 3.501 & 1.926 & \\
\hline OCDF & 0.001 & 0.000 & 351.773 & 0.000 & 0.352 & \\
\hline Total PCDFs & & 350.139 & $1,030.88$ & 3.501 & 7.143 & $100 \mathrm{pg}-\mathrm{TEQ} / \mathrm{Sm}$ \\
\hline 2,3,7,8-TCDD & 1 & 0.000 & 0.000 & 0.000 & 0.000 & \multirow{9}{*}{$\begin{array}{l}>4 \text { ton } / \mathrm{hr} \text {, } \\
\text { new plant }\end{array}$} \\
\hline 1,2,3,7,8-PeCDD & 0.5 & 0.000 & 0.000 & 0.000 & 0.000 & \\
\hline $1,2,3,4,7,8-\mathrm{HxCDD}$ & 0.1 & 0.000 & 0.000 & 0.000 & 0.000 & \\
\hline $1,2,3,6,7,8-\mathrm{HxCDD}$ & 0.1 & 0.000 & 0.000 & 0.000 & 0.000 & \\
\hline 1,2,3,7,8,9-HxCDD & 0.1 & 0.000 & 0.000 & 0.000 & 0.000 & \\
\hline $1,2,3,4,6,7,8-\mathrm{HpCDD}$ & 0.01 & 766.867 & 729.111 & 7.669 & 7.291 & \\
\hline OCDD & 0.001 & 937.334 & 701.192 & 0.937 & 0.701 & \\
\hline Total PCDDs & & $1,704.201$ & $1,430.303$ & 8.606 & 7.992 & \\
\hline Total & & $2,054.340$ & $2,461.183$ & 12.107 & 15.135 & \\
\hline
\end{tabular}

HTPG: high temperature and pressure gasification, WHO: World Health Organization, TEF: toxic equivalency factors, TEQ: toxicity equivalency quantity, PCDF: polychlorinated dibenzofuran, PCDD: polychlorinated dibenzodioxin.

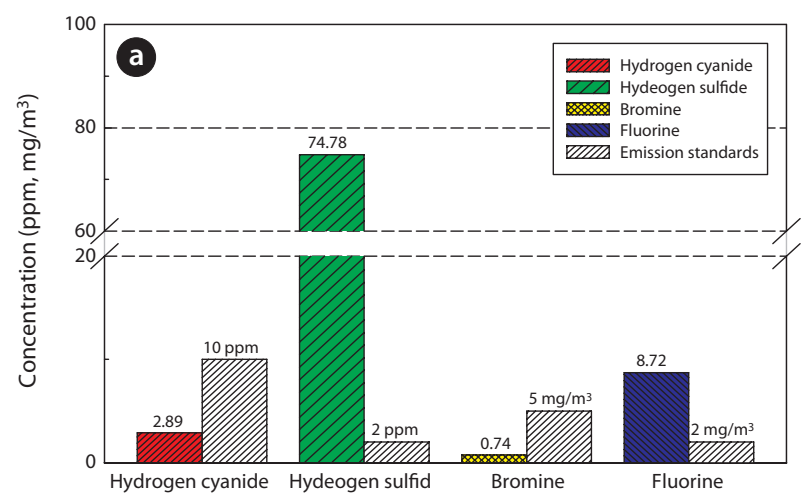

Pollutants

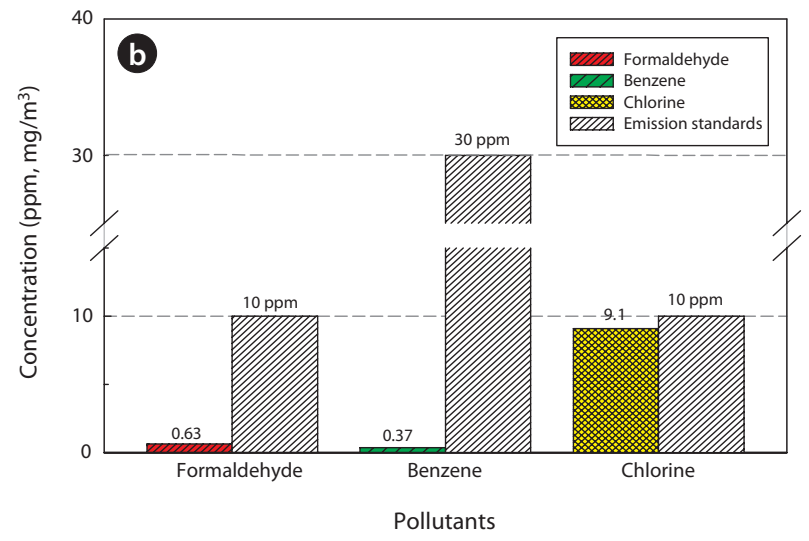

Fig. 10. Air pollutants detected in the synthetic gas generated from the high temperature and pressure gasification reactor; (a) hydrogen cyanide, hydrogen sulfide, bromine, and fluorine, (b) formaldehyde, benzene, and chlorine. equately because the concentrations were under the new Korean emission standard of $100 \mathrm{pg}$-TEQ $/ \mathrm{Sm}^{3}$ for an incinerator scale of more than 4 ton/hr.

\subsection{Air Contaminants}

Table 7 and Fig. 10 show the concentrations of pollutants emitted from the HTPG reactor. The Korean emission standards shown in Table 7 are applicable to an incinerator operation with a capacity of over 2 ton $/ \mathrm{hr}$. The majority of pollutants were found to be at much lower concentrations in comparison to those al-

Table 7. Air pollutants in the synthetic gas generated from the HTPG reactor

\begin{tabular}{lcc}
\hline \multicolumn{1}{c}{ Pollutants } & $\begin{array}{c}\text { Average detected } \\
\text { values }\end{array}$ & $\begin{array}{c}\text { Korean emission } \\
\text { standards }\end{array}$ \\
\hline $\mathrm{NH}_{3}(\mathrm{ppm})$ & $\mathrm{ND}$ & $<100$ \\
$\mathrm{HCl}(\mathrm{ppm})$ & $\mathrm{ND}$ & $<30$ \\
$\mathrm{Cl}_{2}(\mathrm{ppm})$ & 9.1 & $<10$ \\
$\mathrm{CS}_{2}(\mathrm{ppm})$ & $\mathrm{ND}$ & $<30$ \\
$\mathrm{SOx}(\mathrm{ppm})$ & $\mathrm{ND}$ & $<30$ \\
$\mathrm{HCHO}(\mathrm{ppm})$ & 0.63 & $<10$ \\
$\mathrm{C}_{6} \mathrm{H}_{6}(\mathrm{ppm})$ & 0.37 & $<30$ \\
$\mathrm{C}_{6} \mathrm{H}_{5} \mathrm{OH}(\mathrm{ppm})$ & $\mathrm{ND}$ & $<10$ \\
$\mathrm{H}_{2} \mathrm{~S}(\mathrm{ppm})$ & 74.78 & $<2$ \\
$\mathrm{HCN}(\mathrm{ppm})$ & 2.89 & $<10$ \\
Vinyl chloride $(\mathrm{ppm})$ & $\mathrm{ND}$ & - \\
Fluorine $\left(\mathrm{mg} / \mathrm{m}^{3}\right)$ & 8.72 & $<2$ \\
Bromine $\left(\mathrm{mg} / \mathrm{m}^{3}\right)$ & 0.74 & $<5$ \\
Mercury $\left(\mathrm{mg} / \mathrm{m}^{3}\right)$ & $\mathrm{ND}$ & $<0.1$ \\
Arsenic $\left(\mathrm{mg} / \mathrm{m}^{3}\right)$ & $\mathrm{ND}$ & $<0.5$ \\
\hline
\end{tabular}

HTPG: high temperature and pressure gasification, ND: not detected. 
lowed in the regulations. Only 5 out of 11 gaseous pollutants and 2 out of 4 heavy metals were detected in the analyses. Of the gaseous contaminants, $74.78 \mathrm{ppm}$ of $\mathrm{H}_{2} \mathrm{~S}$ was detected, which exceeded the Korean emission standard of 2 ppm by 34 times. Furthermore, the concentration of $\mathrm{Cl}_{2}$ was $9.1 \mathrm{ppm}$, which was close to the Korean emission standard of $10 \mathrm{ppm}$. The fluoride compound was $8.72 \mathrm{mg} / \mathrm{m}^{3}$, which is more than 4 times the permissible Korean emission standard of $2 \mathrm{mg} / \mathrm{m}^{3}$. However, concentrations of other heavy metals were much lower than those permissible in the Korean emission standards or were not detected at all. However, it is believed that the concentrations of the air pollutants emitted could be controlled compared to under those in the Korean emissions standards if air pollution control facilities are established, because the results expressed in this study are the concentrations of proper air pollutants emitted from the HTPG reactor without any air pollution control equipment. Therefore, the experimental conditions suggested in this study are considered as very useful, not only for effectively treating insulating oil containing PCBs, but for obtaining synthetic gas comprised of $\mathrm{CO}$ and $\mathrm{H}_{2}$.

\section{Conclusions}

Insulating oil containing PCBs was converted into harmless synthetic gas via pyrolysis in the HTPG reactor with thermal energy obtained from the combustion of the synthetic gas produced. The results obtained from this study are listed below. 1) During the gasification reaction of the insulating oil waste (20 $\mathrm{kg} / \mathrm{hr}$ ), $59.67 \mathrm{Am}^{3} / \mathrm{hr}$ of synthetic gas was generated, with a heating value of $1,929 \mathrm{kcal} / \mathrm{Sm}^{3}$, when processed under a steady state. The synthetic gas also showed the possibility for use as a fuel gas thanks to the average concentrations (standard deviation) of each gas, which were $\mathrm{O}_{2} 0.27 \pm 0.0119 \%, \mathrm{CO}_{2} 38.63 \pm 3.11 \%$, $\mathrm{H}_{2} 28.42 \pm 1.68 \%$, and CO $35.18 \pm 1.93 \%$. 2) The HTPG system proposed in this study demonstrated high energy efficiency in treatment performance and in the production of synthetic gas generated from the gasification of the insulating oil waste. The stable gasification reaction progressed at around an equivalence ratio of 1.4. 3) Many tetrachlorobiphenyl and octachlorobiphenyl PCBs were detected in the transformer insulating oil, but 12 dl-PCBs were not detected. Only the \#49, \#44, \#52, \#47/75/48 PCB congeners were detected in the synthetic gas generated from the gasification of the insulating oil in the HTPG reactor but 12 dl-PCBs were not detected. 4) The average DRE of the PCBs after gasification of the insulating oil in the HTPG reactor was $99.9939 \%$, and that of the PCBs from the combustor was 99.9999\%. This proves that our HTPG reactor system was very effective for the gasification of insulating oil and the treatment of PCBs contained within the oil. 5) Only 5 gaseous contaminants and 2 heavy metals were detected in the analyses regarding the 11 gaseous contaminants and 4 heavy metals were potentially emitted from the HTPG reactor. It is believed that the concentrations of the contaminants emitted into the air can be controlled to almost zero on the establishment of air pollution control facilities, because the results of this experiment represent the concentrations of air contaminants emitted from the HTPG reactor without the use of air pollution control facilities. Consequently, the experimental conditions suggested in this study are considered very useful for not only the effective treatment of PCBs but also for obtaining synthetic gas comprised of $\mathrm{CO}$ and $\mathrm{H}_{2}$.

\section{Acknowledgments}

This research was supported by a grant (code 08 RTI B-03) from the Regional Technology Innovation Program funded by Ministry of Land Transport \& Maritime Affairs of the Korean government.

\section{References}

1. US Environmental Protection Agency. Polychlorinated biphenyls (PCBs) [Internet]. Cincinnati: US Environmental Protection Agency; c2012 [cited 2012 Aug 30]. Available from: http://www.epa.gov/epawaste/hazard/tsd/pcbs/index.htm.

2. Jensen S, Johnels AG, Olsson M, Otterlind G. DDT and PCB in marine animals from Swedish waters. Nature 1969;224:247250.

3. Breivik K, Sweetman A, Pacyna JM, Jones KC. Towards a global historical emission inventory for selected PCB congeners: a mass balance approach. 1. Global production and consumption. Sci. Total Environ. 2002;290:181-198.

4. United Nations Environment Programme (UNEP) Chemicals. Guidelines for the identification of PCBs and materials containing PCBs. Geneva: UNEP Chemicals; 1999.

5. Hawari J, Demeter A, Samson R. Sensitized photolysis of polychlorobiphenyls in alkaline 2-propanol: dechlorination of Aroclor 1254 in soil samples by solar radiation. Environ. Sci. Technol. 1992;26:2022-2027.

6. Erickson MD, Swanson SE, Flora JD Jr, Hinshaw GD. Polychlorinated dibenzofurans and other thermal combustion products from dielectric fluids containing polychlorinated biphenyls. Environ. Sci. Technol. 1989;23:462-470.

7. Consonni S, Vigano F. Waste gasification vs. conventional waste-to-energy: a comparative evaluation of two commercial technologies. Waste Manag. 2012;32:653-666.

8. Okumura Y, Sugiyama Y, Ikazaki K. Evolution prediction of coal-nitrogen in high pressure pyrolysis processes. Fuel 2002;81:2317-2324.

9. National Institute of Environmental Research. Standard operating procedure of PCBs in transformer oil. Seoul: National Institute of Environmental Research; 2004.

10. Ministry of Environment (Korea). Korean waste official method. Gwacheon: Ministry of Environment; 2004.

11. Van den Berg M, Birnbaum L, Bosveld AT, et al. Toxic equivalency factors (TEFs) for PCBs, PCDDs, PCDFs for humans and wildlife. Environ. Health Perspect. 1998;106:775-792.

12. Smoot LD, Smith PJ. Coal combustion and gasification. New York: Plenum Press; 1985.

13. Institute for Advanced Engineering. Gasification/melting process development for treating combustible wastes. Gwacheon: Ministry of Commerce, Industry and Energy; 2005.

14. Institute for Advanced Engineering. Gasification/melting process development for treating combustible wastes (5 ton/ day-class). Gwacheon: Ministry of Education, Science and Technology; 2002.

15. Schobel A, Class AG, Krebs L, Braun-Unkhoff M, Wahl C, Frank P. Thermal destruction of benzene. Chemosphere 2001;42:591-9.

16. Aracil I, Font R, Conesa JA. Semivolatile and volatile compounds from the pyrolysis and combustion of polyvinyl chloride. J. Anal. Appl. Pyrolysis. 2005;74:465-489. 